\title{
Impact of low (zero) carbon power systems on power system protection: a new evaluation approach based on a flexible modelling and hardware testing platform
}

ISSN 1751-8644 doi: 0000000000 www.ietdl.org

\author{
Ruiqi Li ${ }^{1}$, Jiebei Zhu ${ }^{2 *}$, Qiteng Hong ${ }^{1}$, Campbell Booth ${ }^{1}$, Adam Dyśko ${ }^{1}$, Andrew Roscoe ${ }^{3}$, Helge Urdal ${ }^{4}$ \\ ${ }^{1}$ Department of Electronic and Electrical Engineering, University of Strathclyde, Glasgow, United Kingdom \\ ${ }^{2}$ School of Electrical and Information Engineering, Tianjin University, Tianjin, China \\ Siemens Gamesa Renewable Energy, Glasgow, United Kingdom \\ 4 Urdal Power Solution Ltd, Otley, United Kingdom \\ *E-mail: zhujiebei@hotmail.com
}

\begin{abstract}
This paper presents a flexible model and testing arrangement that can be used to mimic the fault infeed characteristics of power electronics converters and evaluate the performance of transmission protection schemes to faults when the system is "converter-dominated". That is, sources (e.g. renewables) and infeeds (e.g. HVDC interconnectors) that are interfaced to the main power system via converters. Actual protection relays are injected, in real time, using the outputs of the various fault simulations. A range of potential protection issues, including slow tripping, erroneous discrimination and non-operation, are illustrated for particular scenarios. The main contributions of the paper include knowledge of how different protection schemes may be affected by converter-interfaced sources and guidance on possible solutions to the observed problems. Two solution options are highlighted: changes to the fault detection methods used within relays, and/or defining the fault-response elements of future grid codes (and therefore future converter fault responses) to ensure that existing protection schemes will not be adversely affected in future low-carbon, converter-dominated systems.
\end{abstract}

\section{1}

\section{Introduction}

Power electronics converters, which are used to facilitate the integration of renewable energy to AC grids and which underpin HVDC transmission networks, will play a growing and critical role in future power systems [1]. National Grid (NG), the system operator in Great Britain, has stated that $75 \%$ of electricity supply can be provided from renewables by 2030 according to the UK Future Energy Scenarios document [2]. The maximum instantaneous power from renewable sources could be even greater than this figure [3]. As recently as 1st April 2019, NG stated that it would be capable of operating a "zero carbon" power system by 2025 [4].

The ambitious decarbonisation plans of the UK and other countries may bring significant operational challenges. Unlike synchronous generators (SG), converter-interfaced sources are not capable of providing sustained large fault currents [5]. Based on the studies reported in the System Operability Framework document [6], NG has raised the concern that the existing protection schemes may no longer be sufficiently effective within power systems dominated by converters. At present, there is no clearly defined or universally accepted converter fault behaviour. The Network Code published by ENTSO-E [7] has specified how converters should provide "maximum" reactive current and "fast" fault current, but the terms maximum and fast are ambiguous and not defined explicitly. As a result, it is delegated to national system operators to define and elaborate the specific requirements at the national level.

Multiple research studies have been performed to investigate the network protection challenges related to the integration of nonsynchronous generation sources. [8] has conducted studies on how converters should behave under faults and it is stated that this issue requires further exploration. In [9], protection issues in an AC grid due to fault current injections from HVDC networks are discussed, but the paper focuses on distance protection zone boundaries and how they might be affected from renewable infeeds and the paper is somewhat limited in scope. Issues associated with changing "directions" of fault currents for close-up faults next to wind farms are demonstrated in [10]. Studies in [11-14] describe how a converter's control system and its limited current output can affect the apparent impedance as "seen" by distance protection for resistive faults. The operation of relays located at grid integrated wind farms is studied in [15], conclusions have been drawn that certain protection elements are not working properly due to the generation's fault behaviour. [16] shows how certain converter control strategies may adversely impact relay performance. Studies in [17] show that traditional protection schemes using negative sequence current measurements are not reliable with converter-interfaced source dominated system. In [18] the possible protection challenges arising from converters are listed.

While many of the papers mentioned above investigate the topic associated with protection challenges due to the integration of converter-interfaced sources, they only focus on specific aspects and there is no wide-ranging and systematic study of the general influence of converter-interfaced sources on transmission protection. It is therefore necessary to investigate when and how protection systems, including both modern numerical systems and legacy electro-mechanical schemes, may be affected by the introduction of converter-interfaced sources with different types of responses to faults.

In this paper, a flexible and programmable voltage sourced converter (VSC) model with dedicated control systems capable of producing adjustable fault responses in a quantifiable manner has been developed. The simulated voltage and current waveforms using the developed VSC model can be injected into physical protection relays using secondary injection amplifiers. An automatic testing system has been developed to investigate the operation and response of transmission network protection under high and variable penetrations of converter-interfaced sources of energy (and fault current during faults). Wide-ranging systematic studies have been performed to investigate the general influence of converter-interfaced sources on the performance of distance protection systems using realistic 
network data from the GB transmission system (including transmission lines and the corresponding power flow/fault level data). Potential solutions and risk mitigation strategies are then presented with reference to the results of the conducted and reported studies. Therefore, this paper offers a novel and timely solution with a systematic testing method and a flexible VSC model to facilitate comprehensive evaluations of protection performance under operation conditions with different penetration levels of renewables. The developed VSC model and the testing method presented in the paper can be a valuable tool for future grid code development where desirable converter fault behaviours can be defined and quantified to ensure reliable operation of the protection system.

The paper is organised as follows: Section II presents the development of the converter model for investigation and testing of protection relay performance with different assumed converter behaviours during faults; Section III presents the test system and methodology for evaluating the relay performance using the developed VSC model; Case studies are presented in section IV. Section V highlights key findings and discusses potential solutions for mitigating the impact of converter-interfaced sources on the protection systems. Conclusions are presented in section VI

\section{Development of a flexible converter model}

A converter's fault response is directly impacted by its control system. The exact details of the required converter's fault response shall be defined through the grid/network codes. For example, the requirements for fault current provision may be different in a relatively weak power system (e.g. the GB system in future with lots of renewables) and a strong system (e.g. France, dominated by nuclear and therefore large SG). A key challenge is to determine the actual requirements, and design methods to test compliance with those requirements. These are not simple tasks.

Therefore, to aid these tasks, an adjustable and reliable converter model, capable of generating a range of V/I outputs under grid disturbances has been developed. By adjusting the configuration of the model, the fault responses can be varied widely from a number of perspectives. Using a secondary injection set in the laboratory, the performance of relays in response to the simulated fault voltages and currents can then be monitored and evaluated.

\subsection{Overview of grid code requirements}

In order to develop a converter model with credible behaviours, it is important to investigate the most recently published requirements. The findings are summarised as follows:

1) Requirements for converters: Through analysing the requirements from the most recently updated ENTSO-E network code documents $[7,19]$ and the requirements from the GB grid code documentation [20] published by NG in 2019, the following points can be summarised:

- There is a general desire for converters to produce fast-rising, high-magnitude and sustained (for at least for $100 \mathrm{~ms}$ or more) current injections in response to network faults while ensuring that the converter remains connected and "rides through" the fault. In [20] a reactive current of $0.65 \mathrm{pu}$ is required to be injected within $60 \mathrm{~ms}$ and up to $1.0 \mathrm{pu}$ under worst case condition (depending on the fault clearance time).

- Converters should be able to provide symmetrical/asymmetrical fast fault current during network faults. The characteristics of the voltage deviation and fault current should be specified.

2) Requirements for protection devices: The GB grid code [20] states that the fault clearance times need not be less than $80 \mathrm{~ms}$ (typically ranging from $80 \mathrm{~ms}$ to $100 \mathrm{~ms}$ ). With typical circuit breaker operation times of $50 \mathrm{~ms}$ [21], this means that faults shall be detected by the protection system in around $30 \mathrm{~ms}$, although many relays can do this in $20 \mathrm{~ms}$ or less. Results of tests concerned with investigating the response of distance protection when the power system is dominated by converter-based sources are presented later in the paper.

\subsection{Converter behaviour during faults}

Converters' behaviour under faults shall follow the requirements from grid codes. converter-interfaced sources can be considered as flexibly controlled current sources capable of outputting current with both active and reactive components independently controlled [22].

The fault response from converters is much different from traditional SG. Under a close-up fault, SG will instantly contribute a fault current at 5-7 pu [21]. In the meantime, a converter can only provide a current of $1-2$ pu $[23,24]$ or even lower than 1 pu under extreme conditions [25]. In some cases, it seems that converters shall produce fault current with a delay (during which there could be an initial dip) and then followed by a ramping up of current [26].

\subsection{Design of the controller for the flexible voltage source converter (VSC) model for protection performance evaluation}

Fig. 1 illustrates the controller for the flexible VSC model for protection performance evaluation. In this example, the VSC system is interfaced with a HVDC system, it generally represents converterinterfaced sources and infeeds. The voltage at the connection point (CP) is tracked and then processed with the phase-locked loop (PLL). Following this, the corresponding phase and frequency information are provided for the Park and Inverse Park transformations which facilitate the VSC control system [27]. A dual sequence control scheme is applied in this system to facilitate the VSC's capability of producing balanced and unbalanced currents, stable power outputs and decreasing voltage ripples of the DC link during network disturbances [28]. Moreover, SG' characteristics under network disturbances can also be imitated by the converter to a certain degree with the aid of this scheme [29], as it is clearly advantageous for the converter to meet the grid code.

The control system is separated into two parts: the outer controller and the current controller. The three-phase voltages $v_{a b c}$ and currents $i_{a b c}$, as measured at the connection point are transformed into $d q$ values $\left(v_{d q}^{p} v_{d q}^{n} i_{d q}^{p} i_{d q}^{n}\right)$ by one positive sequence rotating reference frame and one negative sequence frame, both of which rotate mutually in opposite direction with identical fundamental frequency. The process is illustrated in the following equations:

$$
\begin{aligned}
& v_{d q}^{p}=v_{d}^{p}+j v_{q}^{p}=\frac{2}{3} j e^{-j \omega t}\left(v_{a}+e^{j \frac{2}{3} \pi} v_{b}+e^{-j \frac{2}{3} \pi} v_{c}\right) \\
& v_{d q}^{n}=v_{d}^{n}+j v_{q}^{n}=\frac{2}{3} j e^{-j \omega t}\left(v_{a}+e^{-j \frac{2}{3} \pi} v_{b}+e^{j \frac{2}{3} \pi} v_{c}\right)
\end{aligned}
$$

where $v_{a}, v_{b}$ and $v_{c}$ are three-phase instantaneous voltage measured at $\mathrm{CP} ; v_{d q}^{p}$ is the positive sequence voltage in $d q$ frame; and $v_{d q}^{n}$ is the negative sequence voltage in $d q$ frame.

$$
\begin{gathered}
i_{d q}^{p}=i_{d}^{p}+j i_{q}^{p}=\frac{2}{3} j e^{-j \omega t}\left(i_{a}+e^{j \frac{2}{3} \pi} i_{b}+e^{-j \frac{2}{3} \pi} i_{c}\right) \\
i_{d q}^{n}=i_{d}^{n}+j v_{q}^{n}=\frac{2}{3} j e^{-j \omega t}\left(i_{a}+e^{-j \frac{2}{3} \pi} i_{b}+e^{j \frac{2}{3} p i} i_{c}\right)
\end{gathered}
$$

where $i_{a}, i_{b}$ and $i_{c}$ are three-phase instantaneous current measured at the CP point; $i_{d q}^{p}$ is the positive sequence voltage in $d q$ frame; and $i_{d q}^{p}$ is the negative sequence voltage in $d q$ frame.

The magnitudes of $i_{d q}$ are regulated by the PI controllers with the current control according to the reference values. To achieve the control of $i_{d q}$, the VSC output voltage references $v_{d q}^{p *}, v_{d q}^{n *}$ are computed, taking account of the coupling effect of the VSC phase reactor and transformer.

The relationship between the grid voltage $v_{a b c}$, converter output voltage $v_{a b c}^{*}$ and current value $i_{a b c}$ is as follows:

$$
v_{a b c}^{*}=L \frac{d i_{a b c}}{d t}+R i_{a b c}+j \omega L i_{a b c}+v_{a b c}
$$

Expressing equation (5) above in the $d q$ positive and negative sequence forms yields: 


$$
\begin{aligned}
& v_{d}^{p *}=L \frac{d i_{d}^{p}}{d t}+R i_{d}^{p}-\omega L i_{q}^{p}+v_{d}^{p} \\
& v_{q}^{p *}=L \frac{d i_{q}^{p}}{d t}+R i_{q}^{p}+\omega L i_{d}^{p}+v_{q}^{p} \\
& v_{d}^{n *}=L \frac{d i_{d}^{n}}{d t}+R i_{d}^{n}+\omega L i_{q}^{n}+v_{d}^{n} \\
& v_{q}^{n *}=L \frac{d i_{q}^{n}}{d t}+R i_{q}^{n}-\omega L i_{d}^{n}+v_{q}^{n}
\end{aligned}
$$

The outer controller is applied to generate reference signals for the current controller. This process can be manipulated to manage the converter's $P, Q, V_{D C}, V_{A C}$ or any other desired output [30].

\subsection{Fault response manipulation}

To enable the converter model to emulate different fault characteristics, a fault detection logic function (as shown in Fig. 1) has been developed to automatically detect the types of faults that have occurred and subsequently select the corresponding fault response mode. When the fault type has been detected, the outer control loop as shown in Fig. 1) will feed the corresponding fault current reference signals to the current controllers, which will then regulate the fault current output from the converter.

The per unit value of positive and negative sequence voltages $\left(\left|v_{d q}^{p}\right|,\left|v_{d q}^{n}\right|\right)$ at the CP is measured to enable the detection of faults, where:

$$
\left|v_{d q}\right|=\sqrt{\left(v_{d}\right)^{2}+\left(v_{q}\right)^{2}}
$$

For the detection of balanced faults, the system's controller will monitor both positive sequence voltage $\left|v_{d q}^{p}\right|$ and negative sequence voltage $\left|v_{d q}^{n}\right|$. Balanced fault will typically lead to a positive voltage depression (i.e. $\left|v_{d q}^{p}\right|$ will drop below the normally operating range, which is typically 0.94$)$, while $\left|v_{d q}^{n}\right|$ should remain to be negligible. Therefore, the controller will consider there is a balanced fault if $\left|v_{d q}^{p}\right|$ drops below a threshold $K_{H}$ and $\left|v_{d q}^{n}\right|$ is within a limit of $K_{L}$.

For the unbalanced faults, they will lead to significantly larger $\left|v_{d q}^{n}\right|$ compared with normal operating condition, so by monitoring the magnitude of $\left|v_{d q}^{n}\right|$ and if it is greater than the threshold $K_{L}$, it is considered there is a unbalanced fault. The thresholds $K_{H}$ and $K_{L}$ are configurable to get a balance between sensitivity and safety of the fault detection.

The time delays $T_{D 1}, T_{D 2}$ are applied to avoid incorrect operation due to system transient behaviour. $T_{D 1}$ is selected to be longer than $T_{D 2}$ in order to make sure that the total time for the generation of fault detection signal is dependent on $T_{D 1}$.
Under severe faults, the value of $v_{a b c}$ at the $\mathrm{CP}$ can be too small to be processed by the PLL and the converter will no longer be able to output the required currents without the phase and frequency information. To help resolve this issue, after the detection of severe fault, the PLL is designed to restore its voltage information right before the fault and then calculate out the assumed phase and frequency information for the current stage.

The converters fault response is varied through modifying initial delay, current ramp rate and final fault level. The corresponding parameters and how they can be modified is demonstrated (in exaggerated fashion for illustrative purposes) in Fig. 2. Several characteristics of the fault response can be manipulated within the model. The setting of $T_{D 1}$ from Fig. 1 dictates the initial response delay time.

During a balanced situation, when the desired fault level is selected after the detection, the corresponding $i_{d q}$ reference value for the converter's current control loop can be calculated using equations (3) and (4). During the fault, the output current is regulated to reach its final fault level with a controlled current ramp rate by the limiter.

During an unbalanced situation, the fault detection block shall identify the type of the fault and then configure the outer controller to enable the unbalanced fault response mode. The corresponding reference values for the current outputs shall begin to be calculated. The corresponding $i_{d}$ and $i_{q}$ are selected to allow the converter to output its maximum reactive current (with ramp rate defined by the limiter) for the faulted phase(s) while the current in the healthy phase(s) shall be maintained at nominal values (or load values if less than nominal). The process is divided into the following parts:

1) Detect the fault and the faulted phase(s).

2) Calculate the corresponding $A B C$ currents individually, and ensure that the current in the non-faulted phase(s) remain as per prefault values and current in the faulted phase(s) shall begin ramping up to maximum value.

3) Disassemble the $\mathrm{ABC}$ current into positive sequence and negative sequence components, then calculate the corresponding $d q$ value through park transformation.

\section{Relay Performance Testing Methodology}

\subsection{Layout of the transmission system}

A transmission line model and a protection device with appropriate settings have been used as the basis for investigations. This model has been selected in order to investigate the performance of the converters and protection without overly complicating or overburdening processing of simulations, while retaining an adequate level of fidelity. The layout of the system is depicted in Fig. 3. The system is supplied by a combination of SG and VSC based generation

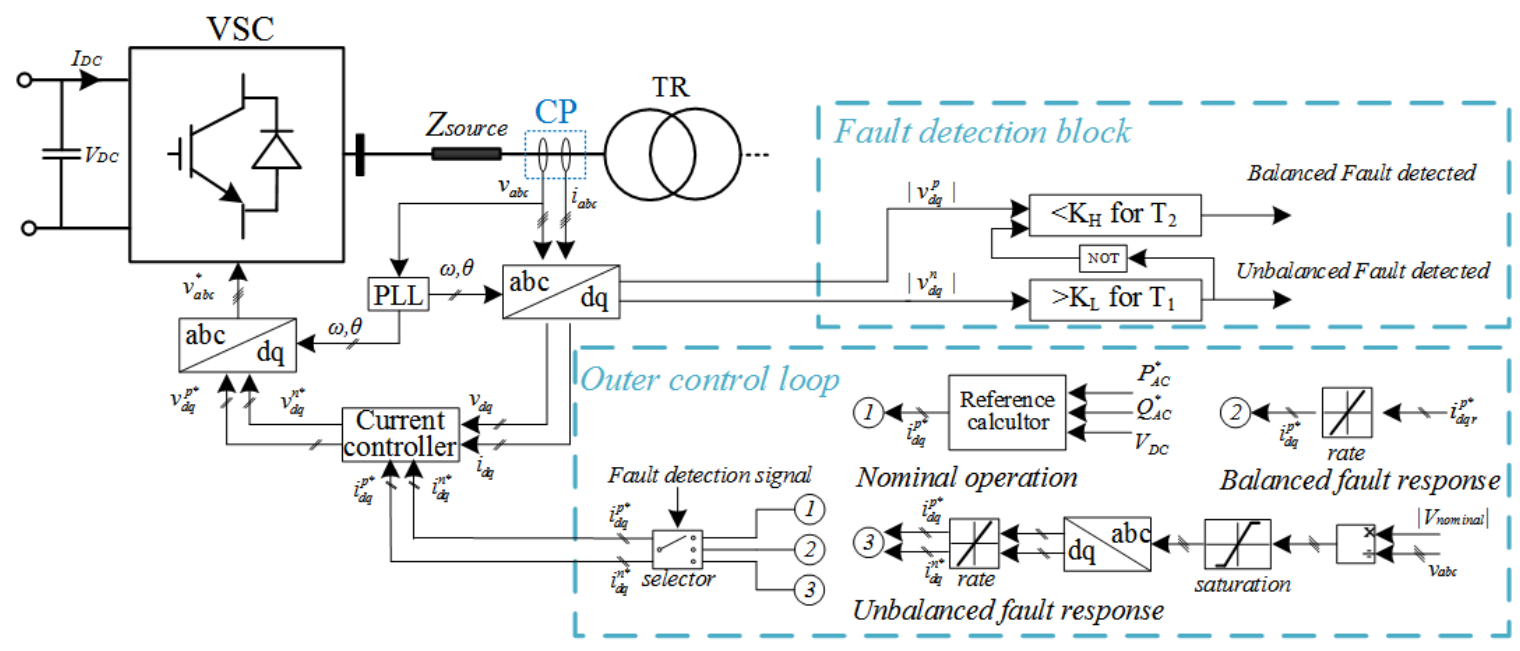

Fig. 1: Layout of the VSC model 


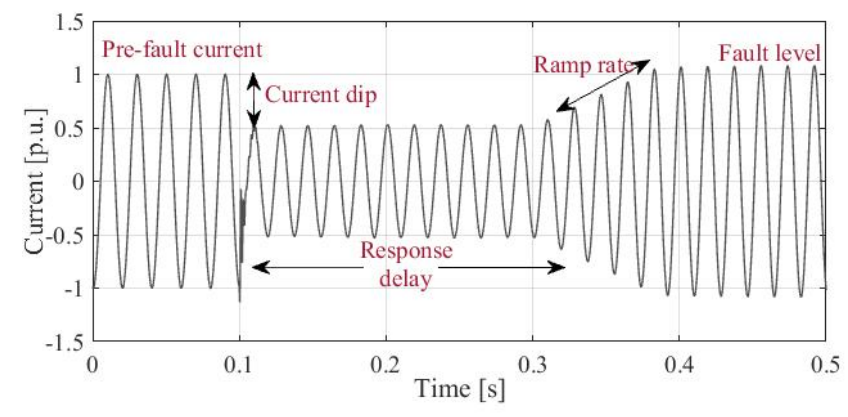

Fig. 2: Controllable output current provided by converter

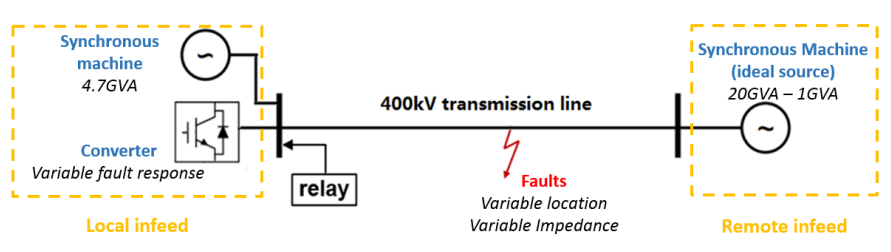

Fig. 3: Model of the transmission system

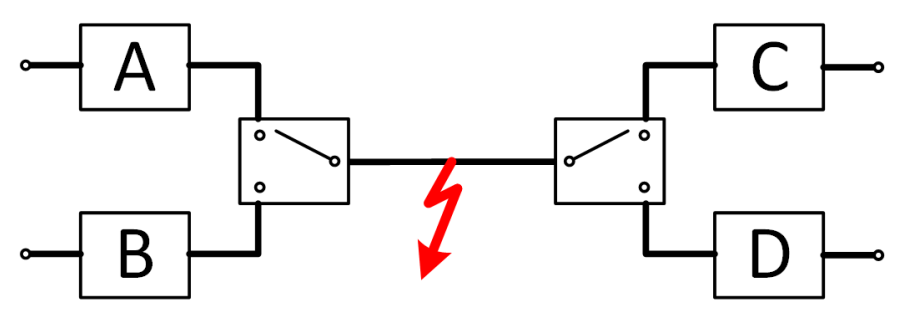

Fig. 4: Model of the transmission line

sources. The power generated from each source $\left(P_{S G}, P_{V S C}\right)$ is all configurable. Note that the fault level from the generation sources is directly affected by their rated power. To avoid confusion, the power generated from each source is set to be their rated power in this system. Based on the thermal rating limited by each source, the thermal penetration level (TPL) of the VSC is defined as following:

$$
T P L=\frac{P_{V S C}}{P_{V S C}+P_{S G}} \times 100 \%
$$

To ensure that the developed testing and evaluation scheme can be applied to different transmission systems with different conditions (and also to facilitate faults at variable distances along lines to be tested), the transmission line model has been disassembled into a 4 different parts as shown in Fig. 4.

Where Line A-C uses a $\pi$ model while B-D uses an $R L$ model. The faulted phase(s) of the transmission line are divided into left and right elements when a fault occurs (assuming a bolted short circuit with no resistance), When the line length is longer than $20 \mathrm{~km}$, the $\pi$ model is selected to represent the system to ensure model fidelity, and when the line length is less than $20 \mathrm{~km}$, the $R L$ model is used in order to reduce the calculation burden without excessively compromising accuracy. The test platform is not extended further in this paper as its complexity may compromise the problem identification for the impact of the power electronic converters on relay operations.

\subsection{Testing arrangement}

The detailed testing arrangement for the assessment of the relay's performance is presented in Fig. 5. To start the testing, the corresponding details (line parameters/nominal voltage/power rating) for the transmission system are required. Then the corresponding

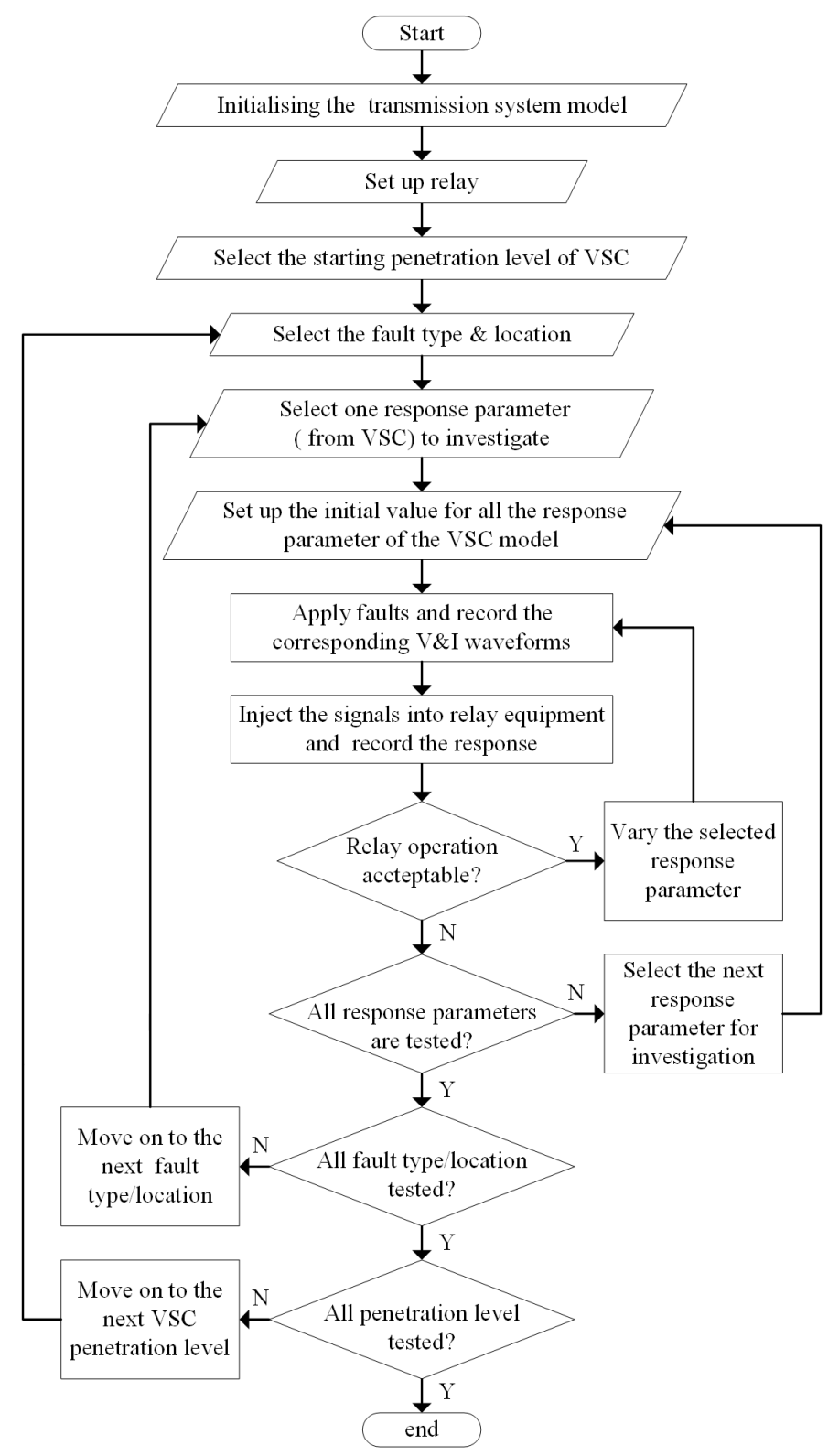

Fig. 5: Relay testing methodology

relay equipment can be set up. Following this the selection of the fault response parameter of the VSC model, faults with selected type and location can therefore be applied to the above system (via simulations in SimPowerSystems).

In the next stage, a .csv file containing discrete values for the three-phase instantaneous voltage and current waveforms (sampled at a frequency of $10 \mathrm{kHz}$ ) is created and replayed in real time into the protection relay using secondary injection equipment. The performance of the relay can therefore be recorded and assessed. The corresponding test facilities are displayed in Fig. 6.

In the particular studies in this paper, the nominal power flows $(1.2 \mathrm{GVA})$ and fault levels provided by the local infeed for the transmission line are from NG documents [31]. When the system is supplied solely by SG, the fault level is set to be 4.7 GVA to represent minimum fault levels as outlined in [31]; a relatively weak local infeed. The remote-end infeed is assumed to comprise SG sources with 20 GVA fault level (i.e. relatively strong remote infeed, sourced from [31]). The selection of the transmission system including its generation rating and fault level data is based on a 'worst case' strategy, and used National Grid's electricity ten year statement [31], system operability framework [6] and the future energy scenarios [2] documents, with a particular transmission line being selected from 


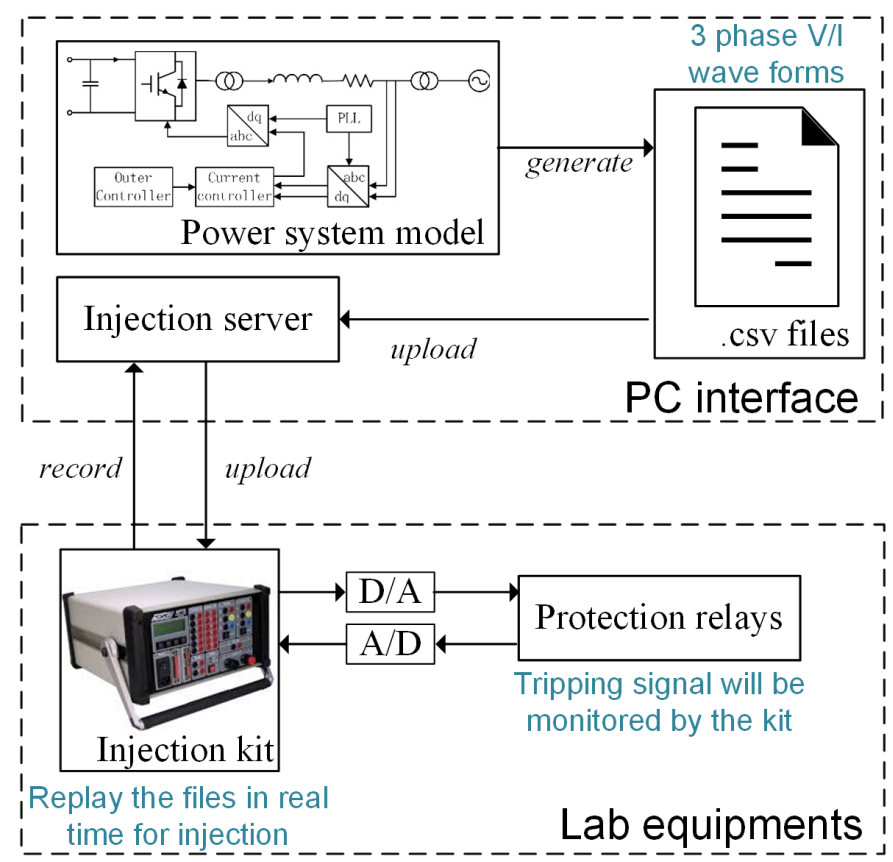

Fig. 6: Secondary injection testing facility

the GB system due to the low fault levels in that area - however, as already mentioned, any line/fault infeed could be characterised easily by changing parameters.

There is a total of four main scenarios (which will be explained in detail later in this paper); each scenario is compared with a base case which assumes that the system is supplied by traditional SG providing relatively high and instantaneous fault currents.

\subsection{Protection relays}

The parameters defining the performance of any protection system are fivefold: reliability (secure and dependable), selectivity (ability to ensure different operation time on different protected zone), operation speed (ensure fast operation within the primary protected zone), simplicity, and economics [32].

Two distance relays (from two different manufacturers) have been tested in this study using secondary injection. The main protection schemes applied within transmission network are distance protection schemes and differential protection schemes. Comparing with differential protection which possess absolute selectivity [33], distance protection is commonly arranged to protect multiple zones with more sophisticated settings and input. Their operating principles can be summarised as following:

During network faults supplied by converter-interfaced sources, the current measured by the relay shall rise immediately and the corresponding voltage will simultaneously drop. The sudden change of the measured data will trigger the relay's starting function to identify the faulted phase. Then the measured V/I shall indicate the distance between the relay and the faulted point. As a non-unit protection, distance relay is configured to act fast to disconnect the fault within its primarily protected zone (zone 1 protection, which is typically $80 \%$ of the protected transmission line), and act with a delayed manner when the fault is outside zone 1 as a backup function. The relays' operation speed, in response to different fault type and locations with different generation sources supplying the fault current, will be tested and be presented in details in the next section.

\section{$4 \quad$ Case studies}

\subsection{Scenario 1: impact of changing converter fault response}

The relay responses to a fault (at a fixed location) with local infeed consisting of a SG only, and then consisting of converters only, and using a range of different converter response characteristics, are monitored and analysed in each scenario. Values for the initial delay, ramp rate and sustained fault levels have been selected based on a combination of evidence [23] [24], and through consultation with experienced engineers. As mentioned in section IV, two distance protection relays (from different manufacturers that are commonly used in the GB transmission system) have been tested and are referred as relay 1 and relay 2 in this paper. Table 1 presents relay tripping times for the first scenario (testing $\mathrm{ABC}$ faults with balanced converter output). The system is $100 \%$ dominated by SG in case 1.1, and then $100 \%$ dominated by VSC converters in case 1.2-1.14.

$T_{1}$ and $T_{2}$ are the tripping times (from the inception of faults to the generation of the tripping signal) of relays 1 and 2 .

As already explained in details in section II, the converters are controlled to react to faults with a fixed initial delay, ramp rate and sustained fault level (note that the current dip function is not employed here, it is an additional option which can be applied when required). In case 1.2, the converter is configured to provide a relatively fast response (with detailed parameters presented in Table 1) and therefore it is selected to be a reference case as a starting point. In case 1.3-1.6, the initial delay is increased from $2 \mathrm{~ms}$ from case 1.2 to $100 \mathrm{~ms}$ in case 1.6 gradually, meanwhile, all the other parameters remain fixed. Then in case 1.7-1.10, the ramp rate is decreased from $1.5 \mathrm{GVA} /$ cycle to $0.1 \mathrm{GVA} /$ cycle while all the other parameters stay the same as in case 1.2. Similarly, in case 1.11-1.14, the effects of changing the final fault level are studied.

As an extension of Table 1, results regarding solid faults applied at $50 \%$ distance of the transmission line are included for all scenarios shown plotted in Fig. 7 (for clarity, instances of non-operation are shown as white columns topped with a red X). The trip times for each relay are measured for four fault types with two converter response modes: for solid 3-phase $\mathrm{ABC}$ faults with balanced converter output $\left(T_{A B C}\right)$; for solid $\mathrm{AB}$ faults with balanced converter output $\left(T_{A B}\right)$; for solid AN faults with balanced converter output $\left(T_{A N}\right)$; for solid AN faults with unbalanced converter output (using a dual sequence controller) $\left(T_{A N}^{*}\right)$. The plots a), b) and c) show the trip times for relay 1 , while d), e) and f) are for relay 2 .

Following conclusions have been drawn based on Table 1 and Fig.

1) For the different relays (with the same settings), certain trip times vary. For the benchmark case study (SG fault infeed), both relays operate similarly with a delay of approximately $20 \mathrm{~ms}$ (as shown in case 1.1 from Table 1). However, when converters are introduced, the relays' performance may be compromised to an extent in the majority of cases. Fig. 7 demonstrates that the operation time of both relays can be impacted seriously in some cases (non-operation of relay 1 in Fig. 7.b-c and a 20ms delay in the operation time of relay 2 in Fig. 7.e).

2) When the system is supplied by converters with relatively fast fault responses and relatively high fault currents, the trip time of relay 1 can be delayed by up to $150 \mathrm{~ms}$ (Fig. 7.a) compared to the benchmark case (SG fault infeed). When the ramp rate and sustained fault level magnitude are decreased beyond certain values, relays may not trip at all (Fig. 7.b-c). The overall performance of relay 2 is not affected as much as that of relay 1 , but it is still compromised as its operation are delayed in most cases (Fig. 7.d-e).

3) The contribution of negative sequence currents from converters (which is only possible for some converters and is dependent on the controller) can lessen the negative impact on relay performance. As shown in Fig. 7.b and Fig. 7.c, without negative sequence current injection (shown as red, blue and purple columns), relay 1 can no longer operate when the VSC is not providing current with sufficient ramp rate/ sustained level. It is clear that, in general, there are many instances of delayed (and in some cases non-) operation. 


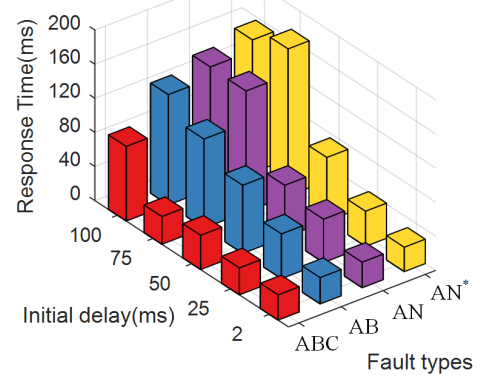

(a)

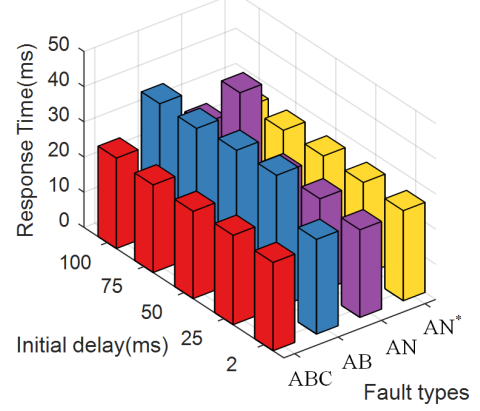

(d)

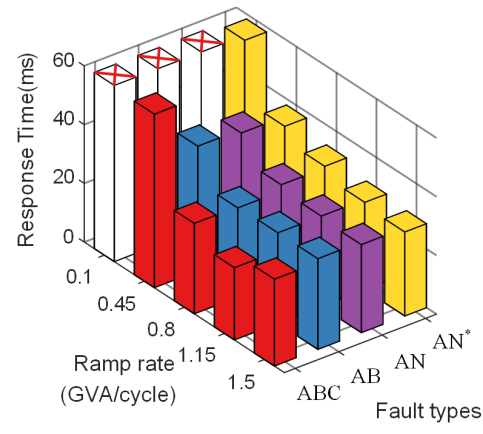

(b)

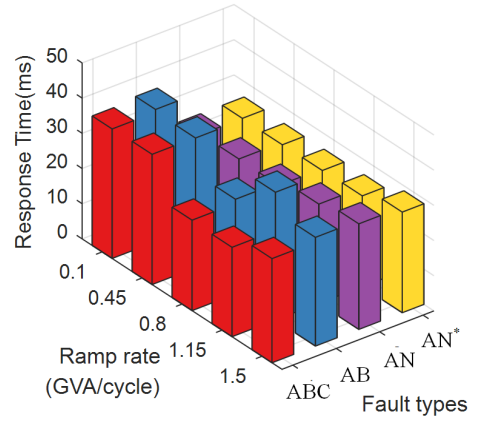

(e)

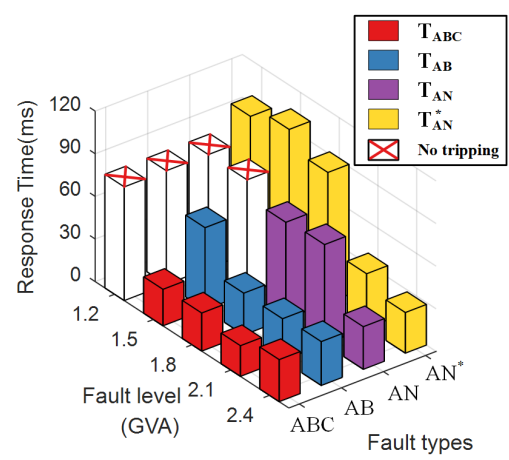

(c)

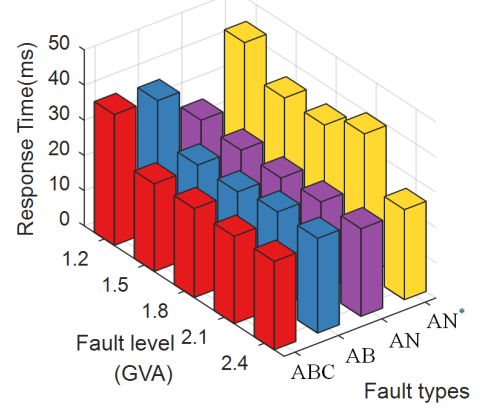

(f)

Fig. 7: Impact of varying converter response parameters - Relay 1: a) initial response delay, b) fault current ramp rate, c) sustained fault level; - Relay 2: d) initial response delay, e) fault current ramp rate, f) sustained fault level.

Table 1 Tripping times (ms) of relays under ABC faults

\begin{tabular}{|c|c|c|c|c|c|c|c|c|c|c|}
\hline \multirow{3}{*}{$\begin{array}{c}\text { Case } \\
\text { number }\end{array}$} & \multirow{3}{*}{$\begin{array}{l}\text { Energy } \\
\text { source }\end{array}$} & \multirow{3}{*}{$\begin{array}{c}\text { Initial } \\
\text { delay (ms) }\end{array}$} & \multirow{3}{*}{$\begin{array}{l}\text { Ramp rate } \\
(\mathrm{GVA} / \text { cycle })\end{array}$} & \multirow{3}{*}{$\begin{array}{c}\text { Sustained } \\
\text { fault level } \\
\text { (GVA) }\end{array}$} & \multicolumn{6}{|c|}{ Fault location } \\
\hline & & & & & \multicolumn{2}{|c|}{$5 \%$} & \multicolumn{2}{|c|}{$50 \%$} & \multicolumn{2}{|c|}{$100 \%$} \\
\hline & & & & & $T_{1}$ & $T_{2}$ & $T_{1}$ & $T_{2}$ & $T_{1}$ & $T_{2}$ \\
\hline 1.1 & $\mathrm{SG}$ & NA & NA & 4.7 & 18.3 & 20.9 & 19.2 & 22.4 & 328.4 & 344.8 \\
\hline 1.2 & VSC & 2 & 1.5 & 2.4 & 35.1 & 25.2 & 29.6 & 25.1 & 329 & 349.9 \\
\hline 1.3 & VSC & 25 & 1.5 & 2.4 & 59.7 & 25.4 & 31.6 & 25.4 & 329.5 & 365.8 \\
\hline 1.4 & VSC & 50 & 1.5 & 2.4 & 58.9 & 25.1 & 40.2 & 24.8 & 329.7 & 455.3 \\
\hline 1.5 & VSC & 75 & 1.5 & 2.4 & 86.6 & 25.3 & 32.5 & 24.9 & 328.6 & 334.8 \\
\hline 1.6 & VSC & 100 & 1.5 & 2.4 & 87.3 & 25.8 & 87.5 & 25.7 & 329.7 & 339.1 \\
\hline 1.7 & VSC & 2 & 1.15 & 2.4 & 37.4 & 25 & 24.6 & 25.4 & 322.9 & 335 \\
\hline 1.8 & VSC & 2 & 0.8 & 2.4 & 58.5 & 25 & 30.8 & 25.7 & 328.1 & 337.6 \\
\hline 1.9 & VSC & 2 & 0.45 & 2.4 & 67.2 & 37 & 59.1 & 37 & 356.9 & 335.8 \\
\hline 1.10 & VSC & 2 & 0.1 & 2.4 & - & 37.6 & _ & 36.8 & - & 334.7 \\
\hline 1.11 & VSC & 2 & 1.5 & 1.8 & 34 & 25.2 & 26.8 & 25.3 & 327.1 & 339.8 \\
\hline 1.12 & VSC & 2 & 1.5 & 1.5 & - & 25.5 & 25.7 & 24.9 & 327.9 & 343.9 \\
\hline 1.13 & VSC & 2 & 1.5 & 1.2 & - & 37.7 & - & 37.2 & - & 339.8 \\
\hline 1.14 & VSC & 2 & 1.5 & 2.4 & 18.3 & 20.9 & 19.2 & 22.4 & 328.4 & 344.8 \\
\hline
\end{tabular}

\subsection{Scenario 2: impact of changing fault locations}

The purpose of this scenario is to investigate relay performance to different fault locations with the local infeed consisting of solely SG then with converters with different response characteristics ("strong" and "weak" converters $V S C_{1}$ and $V S C_{2}$ as defined below).

The two somewhat extreme examples of converter response were chosen to illustrate protection performance under markedly different and presumed "grid code" stipulations that may dictate the fault responses of the converters. $V S C_{1}$ has a relatively low response delay $(2 \mathrm{~ms})$, a high ramp rate $(1.4 \mathrm{GVA} /$ cycle) and a high level of sustained fault current (2.4 GVA). $V S C_{2}$, which has a long response delay $(50 \mathrm{~ms})$, a low ramp rate $(0.45 \mathrm{GVA} / \mathrm{cycle})$ and low level of sustained fault current (1.5 GVA). As for scenario 1 , the relays' responses are tested for four fault types. Following findings are summarised based on the results presented in Fig. 8.

1) Three-phase solid faults: As shown in Fig. 8.a-b, the response of relay 1 is acceptable as the zone 1 reach boundary is at its expected value ( $80 \%$ ), when SG supply fault current. When $V S C_{1}$ ("strong") is dominating, zone 1 reach remains relatively unaffected. When supplied by $V S C_{2}$ ("weak"), the operation of the relay is impacted and a reach error of almost $10 \%$ is introduced. The overall performance of relay 2 is similar to relay 1 . The relay's fault trip time is acceptable when $\mathrm{SG}$ or $V S C_{1}$ supply fault current. However, when $V S C_{2}$ is used, the zone 1 reach is shortened by at least $5 \%$.

2) Phase-phase solid faults: From the Fig. 8.c-d, the performance of relay 1 is acceptable when either SG or VSCs provide the local infeed. However, for relay 2, zone 1 reach is extended by at least $7 \%$ 


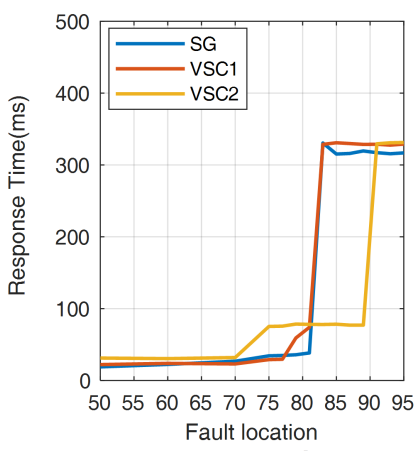

(a) Relay 1: A-B-C faults

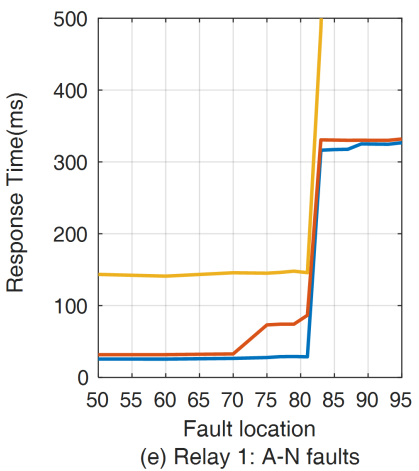

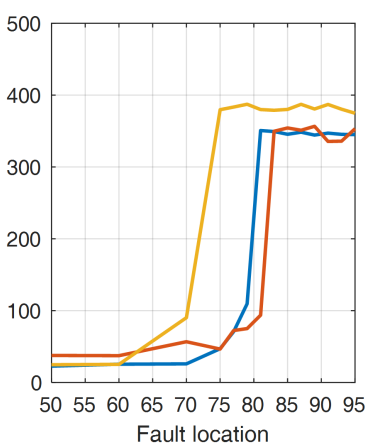

(b) Relay 2: A-B-C faults

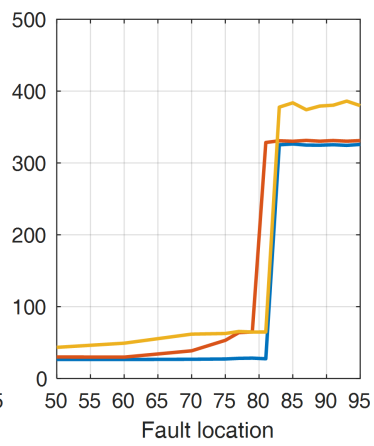

(c) Relay 1: A-B faults

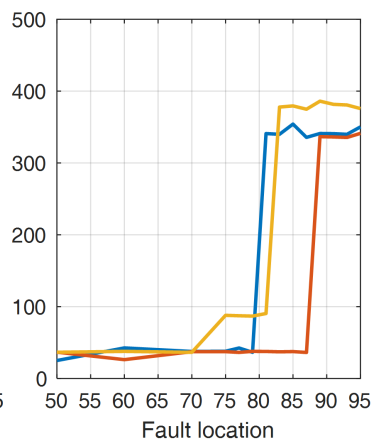

(d) Relay 2: A-B faults
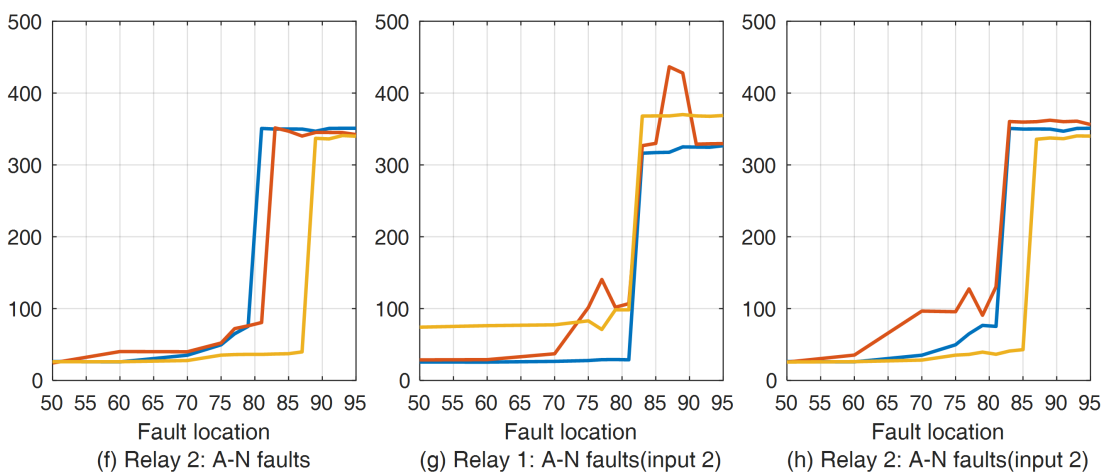

(h) Relay 2: A-N faults(input 2)

Fig. 8: Relay tripping time against fault location (\% of the total line length)

when the system is supplied by $V S C_{1}$ (which is believed to be more "protection friendly"). This is most likely due to the balanced fault current from the converter, discussed further in the next scenario.

3) Phase to ground solid faults: Fig. 8.e-h illustrates results for phase to ground faults. In this case, the non-operation points are demonstrated as faults which are not responded to in $500 \mathrm{~ms}$.

When the converter provides balanced fault current (demonstrated in Fig. 8.e and f), it can be seen that when the system is supplied by $V S C_{1}$, zone 1 reach is acceptable for both relays. When supplied by $V S C_{2}$, relay 1 loses its ability to detect zone 2 faults. In the meantime, relay 2 suffers from zone 1 overreach.

However, when the converter is capable of producing negative sequence current (Fig. 8.g-h), both relays' performance is improved. Relay 1 is now able to detect all faults outside zone 1 , meanwhile, the overreach of relay 2 is reduced (to approximately $5 \%$ in this case). The ability to supply unbalanced output currents can clearly benefit the performance of the relays.

\subsection{Scenario 3: impact of changing converter TPL}

Investigations have been performed to investigate the "tipping point" where the performance of relays shall be significantly compromised by the introduction of converters into the "mix" of generators supply fault currents. In this scenario, relay responses to different converter $T P L$ using $V S C_{1}$ and $V S C_{2}$ are investigated.

In the four sub-scenarios, both converters' $T P L$ range from $0 \%$ to $100 \%$ in steps of $25 \%$. Selected results are presented in Table 2. The relays' trip times in each sub scenario demonstrate that the protection performance is not significantly affected when converter's $T P L$ is lower than $75 \%$. This shows that even a relatively small amount of SG may assist in minimizing the impact of converters upon protection operation (which may show promise for the introduction of synchronous compensators, presently being trialled via the PHOENEX project in GB [34]).

\subsection{Scenario 4: impact of varying remote infeed}

Additional tests were also performed to investigate how the relay at the local end of the line (with converter infeed) might be affected by
Table 2 Tripping times (ms) of relays under solid AN faults

\begin{tabular}{c|l|l|l|l|l|l}
\hline \multirow{2}{*}{$\begin{array}{c}\text { Penetration } \\
\text { Level }\end{array}$} & \multicolumn{5}{|c}{$5 \%$} & \multicolumn{5}{|c}{$50 \%$} & \multicolumn{2}{c}{$100 \%$} \\
\cline { 2 - 7 } & $T_{1}$ & $T_{2}$ & $T_{1}$ & $T_{2}$ & $T_{1}$ & $T_{2}$ \\
\hline $0 \%-V S C 1$ & 18.7 & 20.6 & 18.6 & 25.8 & 319.8 & 335.8 \\
25\%-VSC1 & 20 & 21 & 20.5 & 25.6 & 322.5 & 345 \\
50\%-VSC1 & 19.5 & 20.8 & 22.5 & 26.3 & 324.9 & 336.2 \\
75\%-VSC1 & 20.8 & 21 & 23 & 37 & 323.9 & 340 \\
100\%-VSC1 & 32.2 & 22.7 & 30 & 50 & 32.8 & 341.2 \\
\hline $0 \%$-VSC2 & 18.9 & 21.1 & 18.6 & 26 & 319.8 & 342.5 \\
25\%-VSC2 & 18.6 & 21.1 & 20 & 25.7 & 312.2 & 338 \\
$50 \%-V S C 2$ & 19.6 & 21.3 & 21.2 & 26.3 & 325.2 & 335.3 \\
75\%-VSC2 & 19.4 & 21.2 & 23 & 26.1 & 325.8 & 336.3 \\
100\%-VSC2 & 141.4 & 26.1 & 141.7 & 26.2 & 565.1 & 338.2 \\
\hline
\end{tabular}

varying the remote infeed fault level. Results demonstrate that for most cases (other than when the local end is very weak) the performance of relays is not affected by the remote end infeed, and behaves similarly for all cases as before (with issues still introduced by the converters as outlined previously).

\section{$5 \quad$ Possible solutions}

\subsection{Solutions from a protection relaying perspective}

It has been shown already on multiple occasions that different relays from different manufacturers perform differently even though they have identical settings. According to the relays' user guides, it appears that the main difference lies in the initial fault detection, or "starter" functions. Relay 1 has a system based solely on measured current, while relay 2 has a starter that measures both current and voltage. The current-based starter is adequate for traditional strong power systems, but may not be adequate in future, as there may not be an "impulse" of current at fault inception to initiate relay fault detection (and subsequent tripping) functions. 
Accordingly, for converter-dominated power systems, relays may need to use alternative starting systems based on both voltage and current.

In addition, the main protection function algorithms of relays also affect trip times according to the nature of the fault current provided from sources. As stated in section II, a standard relay testing system regime to emulate worst-case scenarios can be developed and may be viewed as necessary by system operators to prove that protection will operate under all scenarios in future power systems.

\subsection{Solutions from a converter perspective}

Along with the requirements specified in Grid codes, more specific detail can be achieved guided by testing. Provision of unbalanced fault currents when appropriate has also been shown to assist in ensuring adequate relay performance. Some converters only provide balanced currents (regardless of the impedance of system being supplied) and this may require to be changed in future. For instance, converters operating with a "Class 1" Grid-Forming performance as per [35] can provide "instant" fault current response [36] and balanced or unbalanced fault current as required [37].

As for the worst scenarios with relays that can be severely impacted, it can be deducted that the $30 \mathrm{~ms}$ requirement deduced from section II may not be able to be achieved when the converters fault contribution is too low (e.g. 2.1 p.u. based on the worst case presented in this paper) or the converter fault response is delayed by more than $25 \mathrm{~ms}$. These numbers can be seen as quite radical for the converter manufacturers. However, the situation can also be improved by using relays applied with better fault detection systems and/or operating algorithms.

\section{Conclusions}

This paper has presented a systematic methodology for assessing power system protection performance. The proposed approach utilises a flexible model that has been developed to conduct a comprehensive set of tests exploring distance protection response under various fault levels and a range of anticipated converterinterfaced infeed scenarios. Simulated data has been injected into actual relays using both voltage and current injection. The results have confirmed concerns related to protection system performance caused by the increased utilization of converter-interfaced sources and interconnectors.

It has been demonstrated that different relays, with the same operating principles and settings, behave differently and are compromised in a number of different ways. It can be stated with a high degree of confidence that the introduction of converters incapable of contributing "fast" and "high" current during faults introduce a high risk of compromising the performance of relays to some extent, including delayed response, loss of zone discrimination and complete loss of ability to detect certain faults. Further, the reliance on impulse starters for some distance protections and the observed consequent inadequacies of performance leads to a desire to investigate performance of unit protections similarly reliant upon impulse starters. Since a robust and realistic simulation and hardware injection facility has been developed, performance testing regarding a wide range of protection relays should be conducted in the future as outlined below:

1) Comprehensive studies (using injection and the developed system/converter models) of a range of faults/infeeds/converter mixes with a wide range of protection relays including distance, differential and overcurrent.

2) Development of a standard testing/commissioning method (and possibly an industry standard) for evaluating the performance of protection relays in a future low-carbon power system scenario.

\section{References}

1 Telukunta, V., Pradhan, J., Agrawal, A., Singh, M., Srivani, S.G.: 'Protection challenges under bulk penetration of renewable energy resources in power systems: A review', CSEE Journal of Power and Energy Systems, 2017, 3, (4), pp. 365-379
2 National Grid (UK). 'UK Future Energy Scenarios 2018', 2018

3 Urdal, H., Ierna, R., Zhu, J., Ivanov, C., Dahresobh, A., Rostom, D.: 'System strength considerations in a converter dominated power system', IET Renewable Power Generation, 2015, 9, (1), pp. 10-17

4 National Grid ESO (UK). 'Zero carbon operation of Great Britain's electricity system by 2025 ', 2019

5 Li, R., Booth, C., Dyśko, A., Roscoe, A., Urdal, H., Zhu, J. 'Protection challenges in future converter dominated power systems: Demonstration through simulation and hardware tests'. In: International Conference on Renewable Power Generation (RPG 2015). Beijing, China, 2015. pp. 1-6

6 National Grid (UK). 'System Operability Framework', 2016

7 ENTSO-E. 'Network Code on Requirements for Grid Connection applicable to all Generators', 2016

8 Li, R., Booth, C., Dyśko, A., Roscoe, A., Urdal, H., Zhu, J. 'A systematic evaluation of network protection responses in future converter-dominated power systems'. In: 13th International Conference on Development in Power System Protection 2016 (DPSP). Edinburgh, UK, 2016. pp. 1-7

$9 \mathrm{He}$, L., Liu, C.C., Pitto, A., Cirio, D.: 'Distance Protection of AC Grid With HVDC-Connected Offshore Wind Generators', IEEE Transactions on Power Delivery, 2014, 29, (2), pp. 493-501

10 Chen, Y., Wen, M., Yin, X., Cai, Y., Zheng, J.: 'Distance protection for transmission lines of DFIG-based wind power integration system', International Journal of Electrical Power \& Energy Systems, 2018, 100, pp. 438 - 448

11 Alam, M.M., Leite, H., Silva, N., da Silva.Carvalho, A.: 'Performance evaluation of distance protection of transmission lines connected with VSC-HVDC system using closed-loop test in RTDS', Electric Power Systems Research, 2017, 152, pp. $168-183$

12 Alam, M.M., Leite, H., Liang, J., Carvalho, A.d.S.: 'Effects of VSC based HVDC system on distance protection of transmission lines', International Journal of Electrical Power \& Energy Systems, 2017, 92, pp. $245-260$

13 Hooshyar, A., Azzouz, M.A., El.Saadany, E.F.: 'Distance Protection of Lines Emanating From Full-Scale Converter-Interfaced Renewable Energy Power Plants-Part I: Problem Statement', IEEE Transactions on Power Delivery, 2015, 30, (4), pp. 1770-1780

14 Hooshyar, A., Azzouz, M.A., El.Saadany, E.F.: 'Distance Protection of Lines Emanating From Full-Scale Converter-Interfaced Renewable Energy Power Plants-Part II: Solution Description and Evaluation', IEEE Transactions on Power Delivery, 2015, 30, (4), pp. 1781-1791

15 Jain, R., Johnson, B.K., Hess, H.L. 'Performance of line protection and supervisory elements for doubly fed wind turbines'. In: 2015 IEEE Power Energy Society General Meeting, 2015. pp. 1-5

16 Jia, J., Yang, G., Nielsen, A.H., Hansen, P.R.: 'Impact of VSC Control Strategies and Incorporation of Synchronous Condensers on Distance Protection under Unbalanced Faults', IEEE Transactions on Industrial Electronics, 2018, pp. 1-8

17 Nagpal, M., Henville, C.: 'Impact of Power-Electronic Sources on Transmission Line Ground Fault Protection', IEEE Transactions on Power Delivery, 2018, 33, (1), pp. 62-70

18 IEEE/NERC Task Force on Short-Circuit and System Performance Impact of Inverter Based Generation. 'Impact of Inverter Based Generation on Bulk Power System Dynamics and Short-Circuit Performance'. IEEE PES Industry Technical Support Task Force, 2018

19 ENTSO-E. 'Network Code on HVDC Connections', 2016

20 National Grid (UK). 'The Grid Code', 2019

21 Glover, J.D., Sarma, M.S., Overbye, T.: 'Power System Analysis \& Design, SI Version'. (Cengage Learning, 2012)

22 Goksu, O., Teodorescu, R., Bak, C.L., Iov, F., Kjær, P.C.: 'Impact of wind power plant reactive current injection during asymmetrical grid faults', IET Renewable Power Generation, 2013, 7, (5), pp. 484-492

23 Keller, J., Kroposki, B.D. 'Understanding fault characteristics of inverter-based distributed energy resources'. National Renewable Energy Laboratory, 2010

24 Yang, J., Fletcher, J.E., O'Reilly, J.: 'Short-Circuit and Ground Fault Analyses and Location in VSC-Based DC Network Cables', IEEE Transactions on Industrial Electronics, 2012, 59, (10), pp. 3827-3837

25 Jennett, K.I., Booth, C.D., Coffele, F., , A.J.: 'Investigation of the sympathetic tripping problem in power systems with large penetrations of distributed generation', IET Generation, Transmission Distribution, 2015, 9, (4), pp. 379-385

26 Fortmann, J., Pfeiffer, R., Haesen, E., Hulle, F.v., Martin, F., Urdal, H., et al. 'Fault-ride-through requirements for wind power plants in the ENTSO-E network code on requirements for generators', IET Renewable Power Generation, 2015, 9, (1), pp. 18-24

27 Adam, G.: 'Voltage source converter: modulation, control and applications in power systems'. (CreateSpace Independent Publishing Platform, 2013)

28 Roscoe, A.J., Finney, S.J., Burt, G.M.: 'Tradeoffs between ac power quality and dc bus ripple for 3-phase 3-wire inverter-connected devices within microgrids', IEEE Transactions on Power Electronics, 2011, 26, (3), pp. 674-688

29 Zhang, W., Rocabert, J., Candela, J.I., Rodriguez, P., Zhang, W., Rocabert, J., et al.: 'Synchronous Power Control of Grid-Connected Power Converters under Asymmetrical Grid Fault', Energies, 2017, 10, (7)

30 Li, R., Booth, C.D., Dyśko, A., Roscoe, A.J., Zhu, J. 'Development of models to study VSC response to AC system faults and the potential impact on network protection'. In: 2014 49th International Universities Power Engineering Conference (UPEC). Cluj-Napoca, Romania, 2014. pp. 1-6

31 National Grid (UK). 'Electricity Ten Year Statement 2016', 2016

32 Blackburn, J.L., Domin, T.J.: 'Protective relaying: principles and applications'. (CRC press, 2014)

33 Ziegler, G.: 'Numerical Distance Protection: Principles and Applications'. (John Wiley \& Sons, 2011 
34 Nedd, M., Hong, Q., Bell, K., Booth, C., Mohapatra, P. 'Application of synchronous compensators in the GB transmission network to address protection challenges from increasing renewable generation'. In: 2017 CIGRE B5 Colloquium. Bologna,Italy, 2017. pp. 1-6

35 ENTSO-E. 'High penetration of power electronic interfaced power sources (HPoPEIPS)', 2017

36 ENTSO-E 'Fault current contribution from ppms \& hvdc', 2016

37 Roscoe, A.J., Jackson, G., Elders, I.M., McCarthy, J., Burt, G.M 'Demonstration of sustained and useful converter responses during balanced and unbalanced faults in microgrids'. In: 2012 Electrical Systems for Aircraft, Railway and Ship Propulsion (ESARS). Bologna, Italy, 2012. pp. 1-6 